\title{
Finding the Turn
}

\section{Lucy Cash}

"When we're silent and when we stand still we are not resting. We're searching inside ourselves for the turn."

Unconventional forms of collaboration are a core part of my practice as a filmmaker and artist. Collaborations that begin in the form of a conversation and end in the shape of a piece of work.

By not-having-to-be-an-expert I can write from a place on the edge of disciplines, where ideas unfold more slowly (perhaps because they haven't yet condensed into an agreed shorthand), and with more instability. This instability leaves ideas vulnerable to a lack of certainty, but at the same time open to the powerful effect of transformation and re-interpretation: of finding their turning point.

Accordingly, l'd like to respond to Pia Ednie-Brown's beautiful essay, Falling into the surface (towards a materiality of affect), as if Pia and I were collaborating on unfolding my inexpert understanding of her words about architecture. Since Pia and I have never met, this collaboration is a fictitious one. And in keeping with its fictitious nature, I've suggested it here as a conversation: incomplete and fragmented.

Pia E-B: Of constant concern to the discipline of architecture is the effectual nature of the processes of production ... ${ }^{2}$

LC: Within my practice I'm also wondering how the making processes I engage in affect not only a specific piece of work, but also the discipline(s) within which I work. The unconventional collaborative practices I have been involved in often necessitate creating individual systems in order to accommodate a diversity of disciplines. There's a kind of (invisible) autopoiesis which takes place.

One specific area of negotiation within a collaborative system is time:

The time it takes to begin

The time it takes to absorb an idea

The time it takes to respond

The time it takes to respond to what you are seeing and not what you imagine/ assume you are seeing. The time it takes to end.

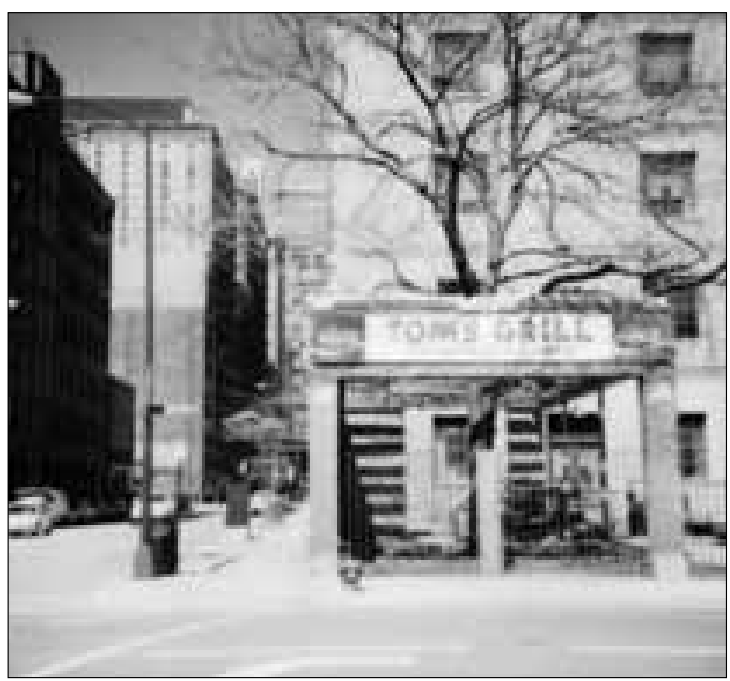

Tom's Grill 
All of this negotiation of time is often hidden and of unexpected duration. I'm thinking about the fact that a building as an event is a long way away from the ephemerality of a performance as event. Not to deny the building as a kind of stage-where people enter and exit and multiple choreographies unfold simultaneously, but rather buildings themselves are (usually) far from ephemeral. And although their surfaces may wear, it's rare to perceive the shifts and adjustments of a building at the molecular level. Yet in his microlecture, The Example of Glass, Goulish does reveal exactly that:

What is glass? Until recently, glass was considered a mostly transparent solid. It behaved like a solid; if struck, it shattered. But then in the ancient cathedrals of Europe it was observed that the tops of windows let in more light than the bottoms. A simple measurement proved that a window of once uniform thickness had grown thicker at the bottom and thinner at the top. Only one explanation exists for this phenomenon. Glass flows in the direction of the pull of gravity, exhibiting the behaviour of a liquid. Thus one cannot conclusively define glass without the inclusion of time. ${ }^{3}$

This first photo shows a Polaroid image that I took in 2003 when I was living and working in Chicago. I used to walk past this tree every day on my way to work, travelling south to north up Dearborne Avenue. At first I used to see the phenomenon of tree and building as a tree growing through the space of an erstwhile roof. Then I began to realise that such a reading relies on a linear logic that imagines the decline of Tom's business, a subsequent dereliction of Tom's building and finally the space for a tree. It could also be possible that Tom's Grill was never a grill business and in fact only ever a "frame" for the tree inside this structure of brickwork. Perhaps, in fact, this tree has a name and the name of this tree is: "Tom's Grill."

If I can postpone the certainty of a logic based on a linear reading of time, then I open up the possibility of other readings of things called trees and buildings. Admittedly this is easier for me to see in relation to my own practice than if I think about the practice of architecture. Making moving image works, for instance, allows the possibility that what was the middle becomes the beginning, and what was the

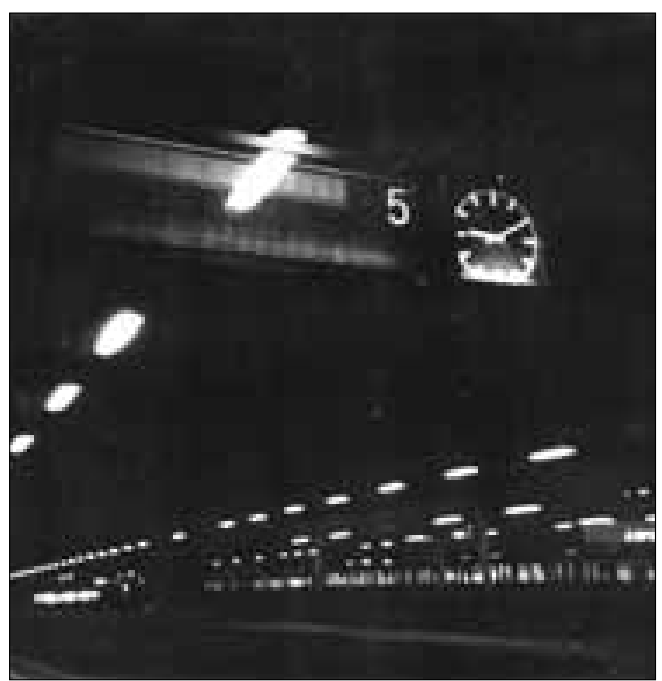

Berlin Station beginning becomes the end. Time can run in more than one direction in a film.

Pia E-B: . . . Design and construction processes are always insinuated in the building itself. As that which steers their formation, they are never not expressedeven if unconsciously... ${ }^{4}$

LC: The unconscious "expression" of process, as you mention, is visible in each piece or project itself, and also, within my practice, in the kinds of relationships that are opened up around each piece. For instance, via an invitation extended by Independent Dance, and alongside four other artists-Becky Edmunds, Gill Clarke, Claudia Kappenberg and Chirstinn 
Whyte - I co-curated a hybrid event, part festival, part exhibition, called What If $\ldots{ }^{5}$ which was held at the Siobhan Davies Studios in London. As a group of artists (and "inexpert" curators), we were interested to explore how we could create a different space of attention for work made by ourselves as well as others (forty artists showed work in What If... ), and how we might curate work based on an embodied sense of an encounter: in-between people and in-between people and art works. We aimed to build an event which offered invitations (as "everything we do is done by invitation" ${ }^{\text {") }}$ ) and proposed the possibility of seeing process and finished works side-by-side. This occurred quite literally: John Smith and Graeme Miller agreed to allow audiences to follow the process of making their video installation Beside the A-Side which took place on the second day of the festival - and more fleetingly, through the unfolding performance of ten writers' responses to the works exhibited?

We had many conversations about time. About how slowing down time might allow us to see different possibilities. Co-curator Claudia Kappenberg coined the term "slowness by fascination," which describes her deeply engaged attention that slows down, allowing her to open up a space between stillness and movement.

A few years back I came across the Finnish architect Juhani Pallasmaa's book about architecture: The Eyes of the Skin (2005). His ideas about the tactility of surfaces - the warmth of wood or the coolness of metal —which invite a haptic rather than visual response to buildings, resonated with me. Since then, I've wondered how often architects get to hang out in the buildings they've designed in order to observe how the invitations or proposals inherent within the building affect the people who use it.

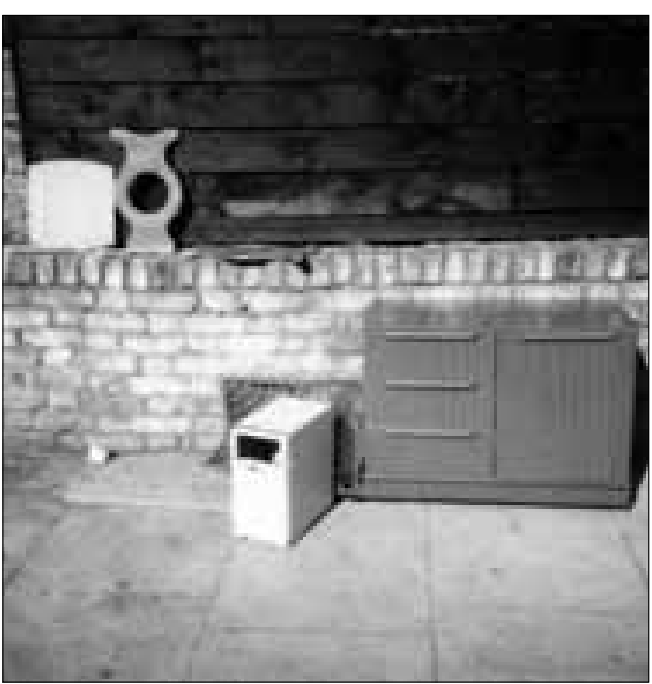

May 1st What kind of unspoken conversations happen between space, buildings and people?

Pia E-B: In a moment of intensive rupture, such as falling, the body twists open into an extra-dimensionality, attaining an extensivity that renders both the 'self' and the object as highly contingent. ${ }^{8}$

LC: An aside, Pia. As a teenager on the way home from ballet class, I was hit by a car whilst crossing the road on a zebra crossing. In my physiological memory of the event, I experienced extreme slowness. You could say that in that single moment, I irrevocably understood slow-motion. I remember my body rising up into the air from the impact of the car, my body passing through the air, flying, flying, flying, flying, until the moment the turn came, and gravity overtook me and once more I was on the ground.

I feel that I have experienced the extra-dimensionality you remark upon in multiple ways. Recently I learnt that on a perceptual level, under extreme duress, our brains take in more 
information than in our ordinary day-to-day perception, which, (like the use of high-speed film recording at, for instance, $100 \mathrm{fps}$ instead of 24fps) results in us experiencing more and slower. In my memory and in my dreams, sometimes the event of the car hitting me is so slow that it comes to a stand-still. Instead of my falling happening like that of the van going over the edge in Inception (2010), it judders to a halt and takes place in still images like my own personal version ofLa Jetée (1962). Time has

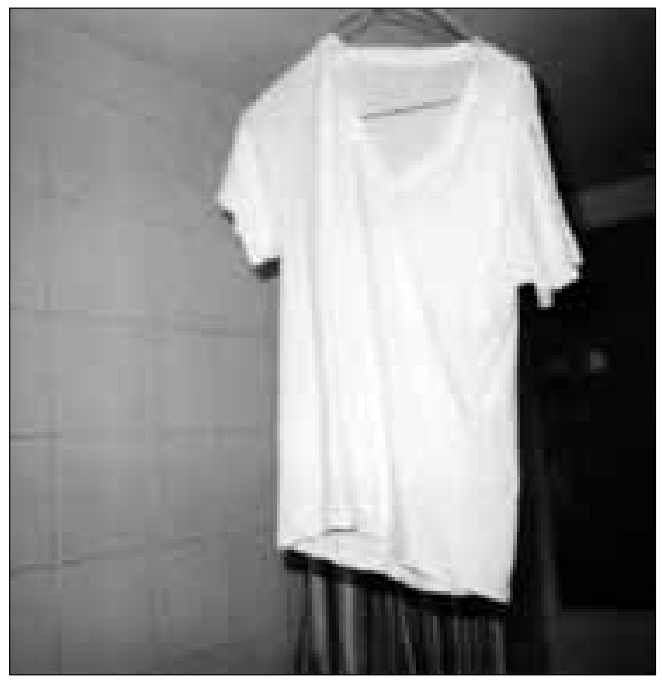

April 20th stretched itself, and this moment (twenty-five years ago now) is still on-going in my foundation, in my skeleton. Because just as the material of glass gives way to gravity, so have my bones absorbed and responded to the dynamic force-of-car impact. An invisible (to others), slight twist reverberates through my right side. If I was a building and needed to attempt to maintain stillness, l'd be leaning sideways through the effort.

Pia E-B: Art does not reproduce the visible; rather, it makes visible. ${ }^{9}$

LC: Pia, when you quote Paul Klee, a quote I like very much, it brings two other quotes to my mind. Another by Paul Klee: "A line is a dot that went for a walk."10 And one by Robert Bresson describing his work as, "A visible parlance of bodies, objects, houses, roads, trees, fields."11

Klee's characterisation of the line through its movement, reminds me of the inherent, gestural quality of mark-making - of how the handiwork of a work can always be uncovered. Of how we can feel the presence of the person holding a camera as much as imagine the hand that held the calligrapher's pen or the painter's brush.

Sometimes I forget to look for the handiwork of a building. Like Pallasmaa's writing, your writing reminds me to re-focus my attention so that I can see the touch of a hand/s on a much larger scale.

As you might imagine, the act of conversing is something I hold dear. This is because it allows for an exchange with another, and also because exchange allows for a shift of position, a different point of view. Bresson's quote allows me to imagine different kinds of conversation - that the bodies and objects, trees and fields in my work might have a particular manner of speaking, set in motion by me, but also beyond what I might have intended.

Art-making as a conversation: an unpredictable form, full of movement which meanders, takes a walk, changes rhythm ... all the while revealing delicate and particular patterns of thought which fall in and out of silence.

Dan Beachy-Quick, a poet and writer based in Chicago, wrote a "primer" to the films I've made with Goat Island; he brings attention to the invisible beneath the visible and reminds me that what you can see is only half the story: 
"Our movements trace our complexity. When we're silent and when we stand still we are not resting. We're searching inside ourselves for the turn."12

Lito Walkey stands still on one leg, with the other knee raised to a right angle for the duration of two James Taylor songs (or 7 3/4 minutes) in Goat Island's eighth performance When will the September Roses Bloom / Last Night Was Only A Comedy (2005).

This image appears as an extended hiatus and was appropriated as a "found" action from Institute Benjamenta — a film by the Brothers Quay (1995). The original action was part of a series, practised within a strange, dream-like school for the training of servants.

Alongside simply being an interruption in continuity, a hiatus can be a break in pronunciation, a break

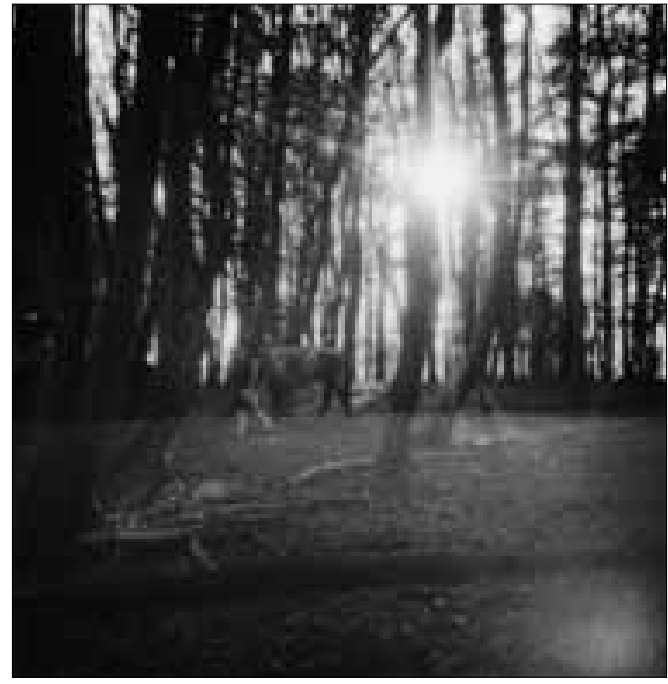

April 19th between adjacent vowels in the sounding of a word.

Lito is left to stand by herself, her arms pointing down by her sides but slightly apart from her body. The deliberate and delicate tension in her arms drawing our eyes both away from and towards the tension in her thigh held perpendicular to the floor. She evokes an image of concentrated stillness and yet we gradually begin to perceive how much movement is involved in maintaining this stillness. After a while we begin to realise that she is creating the stillness outside of herself.

The stillness she creates has a shape and a weight, a rhythm and a structure. It makes visible a flow of constantly shifting invisible images: a servant ... a cowboy ... a punishment ... a statement ... a building ... a bridge ... a machine ... a tree ... a leaf ... a bird ... a child ... a falling ...

\section{References}

Beachy-Quick, Dan. "A Primer to the Films of Goat Island." Unpublished gallery text on the occasion of the Betty Rymer Faculty Sabbatical Exhibition, 2006.

Bresson, Robert. Notes on the Cinematographer . Los Angeles: Green Integer, 1997.

Cage, John. Acceptance speech for Carl Sczuka Prize for Roaratorio: An Irish Circus on Finnegans Wake. Donnaueschingen, 1979.

Ednie-Brown, Pia. "Falling into the Surface (toward a materiality of affect)." Hypersurface Architecturell 69, no. 9/10 (1999): 8-11.

Goat Island. When Will the September Roses Bloom? / Last Night Was Only A Comedy, 2005. Performance.

Goulish, Matthew. 39 Microlectures: In Proximity of Performance. London: Routledge, 2000.

Inception. Directed by Christopher Nolan. USA: Warner Bros Pictures, 2010.

Institute Benjamenta or This Dream People Call Human Life. Directed by Steven Quay and Timothy Quay. UK: Image Forum, 1995.

Klee, Paul. Notebooks, Vol 1: The Thinking Eye. Edited by J. Spiller. Translated by R. Manheim. London: Lund Humphries, 1961.

La Jetée. Directed by Christ Marker. France: Argos Films, 1962.

Pallasmaa, Juhani. The Eyes of the Skin: Architecture and the Senses. Chichester: Academy Editions Ltd, 1996. 


\section{Notes}

1. Quick,"A Primer," 1.

2. Ednie-Brown, "Falling into the Surface," 8.

3. Goulish, 39 Microlectures, 44

4. Ednie-Brown, "Falling into the Surface," 8.

5. What If... Festival. Siobhan Davies Space, April 7-11, 2010, www.whatiffestival.co.uk.

6. Cage, Carl Sczuka Prize acceptance speech.

7. Writers were invited to present / perform their writing over the weekend of What If ... Some writersparticularly Kyra Norman — chose to present daily versions of their writing, generously allowing us to watch the folds and turns in their thinking. The ten writers subsequently revised their responses, which appear in a special edition of Dance Theatre Journal 24.1 (2011).

8. Ednie-Brown, "Falling into the Surface," 10.

9. Paul Klee, cited in Ednie-Brown, "Falling into the Surface," 11.

10. Klee, Notebooks: Vol 1: The Thinking Eye, 111.

11. Bresson, Notes on the Cinematographer, 22.

12. Beachy-Quick, "A Primer," 2. 